\title{
Evaluation of AMSR-E soil moisture product based on ground measurements over temperate and semi-arid regions
}

\author{
C. Gruhier, ${ }^{1}$ P. de Rosnay, ${ }^{1,2}$ Y. Kerr, ${ }^{1}$ E. Mougin, ${ }^{1}$ E. Ceschia, ${ }^{1}$ J.-C. Calvet, ${ }^{3}$ \\ and P. Richaume ${ }^{1}$ \\ Received 17 January 2008; revised 25 March 2008; accepted 1 April 2008; published XX Month 2008.
}

[1] Soil moisture (SM) products provided by remote sensing approaches at continental scale are of great importance for land surface modeling and numerical weather prediction. Before using remotely sensed SM products it is crucial to validate them. This paper presents an evaluation of AMSR-E (Advanced Microwave Scanning Radiometer - Earth Observing System) SM products over two sites. They are located in the south-west of France and in the Sahelian part of Mali in West Africa, in the framework of the SMOSREX (Surface Monitoring Of Soil Reservoir Experiment) and AMMA (African Monsoon Multidisciplinary Analysis) projects respectively. The most representative station of the four stations of each site is used for the comparison of AMSR-E derived and in-situ SM measurements in absolute and normalized values. Results suggest that, although AMSR-E SM product is not able to capture absolute SM values, it provides reliable information on surface SM temporal variability, at seasonal and rainy event scale. It is shown, however, that the use of radiometric products, such as polarization ratio, provides better agreement with ground stations than the derived SM products. Citation: Gruhier, C., P. de Rosnay, Y. Kerr, E. Mougin, E. Ceschia, J.-C. Calvet, and P. Richaume (2008), Evaluation of AMSR-E soil moisture product based on ground measurements over temperate and semi-arid regions, Geophys. Res. Lett., 35, LXXXXX, doi:10.1029/2008GL033330.

\section{Introduction}

[2] Soil moisture (SM) strongly influences and interacts with the land surface processes that control the land surface fluxes. Remote sensing approaches provide spatially integrated information on SM which is valuable information for land surface modeling either in terms of validation or assimilation. Different approaches have been developed for SM remote sensing among which passive microwave at low frequencies is the most promising [Kerr, 2007; Entekhabi et al., 2004; Njoku et al., 2003; Kerr et al., 2001; Njoku and Entekhabi, 1996; Engman, 1990].

[3] The future SMOS (Soil Moisture and Ocean Salinity), is the first mission specifically devoted to SM remote sensing over land surfaces [Kerr et al., 2001]. It will provide measurements of brightness temperature (TB) at L-band, which is shown to be highly sensitive to surface SM with less sensitivity to vegetation cover.

\footnotetext{
${ }^{1}$ Centre d'Etudes Spatiales de la Biosphère, Toulouse, France.

${ }^{2}$ Now at ECMWF, Reading, UK.

${ }^{3}$ Météo-France, Toulouse, France.
}

[4] The Advanced Microwave Scanning Radiometer on 52 Earth Observing System (AMSR-E) of AQUA satellite, is a 53 multi-channel passive microwave instrument. It was 54 launched in 2002 to measure TB at five frequencies in the 55 range of 6.9 to $89 \mathrm{GHz}$.

[5] Before using remotely sensed SM products it is 57 crucial to validate and characterize their ability to provide 58 quantitative estimates of SM. In this study, data from 59 AMSR-E are evaluated. The full year 2005 is considered, 60 which allows investigating AMSR-E suitability at rainfall 61 event and drying cycle temporal scale, as well as at seasonal 62 and inter-seasonal scales. [6] Two sites are used for validating AMSR-E products 64 under contrasted surface and weather conditions, in Europe 65 with the SMOSREX (Surface Monitoring Of Soil Reservoir 66 Experiment) project and in Sahel with the AMMA (African 67 Monsoon Multidisciplinary Analysis) project. The arrange- 68 ment of the SM measuring sites was specifically designed to 69 address the validation of remotely sensed SM. The AMMA- 70 Mali site allows providing an evaluation of AMSR-E SM 71 products in Sahelian area where SM remote sensing is of 72 great importance to investigate feedbacks between SM and 73 precipitation [Koster et al., 2004].

[7] AMSR-E SM products and polarization ratio are 75 evaluated against the best representative SM station of each 76 site. Detailed analysis is conducted to evaluate AMSR-E 77 skill to capture SM peak linked to rainfall events occurrence 78 and SM temporal dynamics from season to year.

\section{Study Regions and Data}

80

[8] Table 1 provides information on the stations loca- 81 tions, as well as the availability of surface SM data at $5-\mathrm{cm} 82$ depth for Day of Year (DOY) 2005.

[9] SMOSREX site is located about $30 \mathrm{~km}$ south of 86 Toulouse in France. It aims at developing and improving 87 the direct and inverse algorithms for SM retrieval from 88 L-band radiometry [de Rosnay et al., 2006]. This site 89 includes two stations (SMB, SMF). Two additional stations, 90 Auradé (AUR) and Lamasquère (LAM) (CarboEurope-IP 91 network, [Dolman et al., 2006]) are used (Table 1). 92

[10] The four stations allow documenting SM in different 93 soil texture and vegetation cover conditions. While SMB, 94 SMF and AUR stations are located on medium loamy 95 textured soils, LAM is on a more clay soil along the Touch 96 river. Vegetation cover are very various with either different 97 types of crops (dominant land use) such as rape (AUR) and 98 triticale (LAM), bare soil (SMB) or natural grass (SMF). 99 
Table 1. SM Stations Location and Data Availability for SMOSREX and AMMA-Mali Sites

\begin{tabular}{|c|c|c|c|c|c|c|}
\hline Location & Station Name & Latitude & Longitude & Start DOY 2005 & End DOY 2005 & DOY Missing \\
\hline \multicolumn{7}{|c|}{ SMOSREX } \\
\hline Auradé & AUR & $43.54^{\circ} \mathrm{N}$ & $1.10^{\circ} \mathrm{E}$ & 1 & 365 & $327-349$ \\
\hline Lamasquère & LAM & $43.49^{\circ} \mathrm{N}$ & $1.23^{\circ} \mathrm{E}$ & 1 & 365 & $103-110,128-132$ \\
\hline SMOSREX Bare soil & SMB & $43.38^{\circ} \mathrm{N}$ & $1.28^{\circ} \mathrm{E}$ & 1 & 365 & $20,231-240,252-257$ \\
\hline SMOSREX Fallow & SMF & $43.38^{\circ} \mathrm{N}$ & $1.28^{\circ} \mathrm{E}$ & 1 & 365 & $17-32$ \\
\hline \multicolumn{7}{|c|}{ AMMA-Mali Sites } \\
\hline Agoufou bottom & AGB & $15.34^{\circ} \mathrm{N}$ & $1.47^{\circ} \mathrm{E}$ & 105 & 365 & None \\
\hline Agoufou top & AGT & $15.34^{\circ} \mathrm{N}$ & $1.47^{\circ} \mathrm{E}$ & 44 & 365 & $179-180$ \\
\hline Bangui Mallam & BAG & $15.39^{\circ} \mathrm{N}$ & $1.34^{\circ} \mathrm{E}$ & 102 & 320 & None \\
\hline Eguérit & EGU & $15.50^{\circ} \mathrm{N}$ & $1.39^{\circ} \mathrm{E}$ & 105 & 321 & None \\
\hline
\end{tabular}

[11] SMOSREX site is located in a temperate climatic region, with well contrasted annual cycle of air temperature and precipitation. 2003-2005 period was characterized by particularly dry conditions. The cumulated rainfall for 2005 was $480 \mathrm{~mm}$ (Figure 1).

\subsection{AMMA-Mali}

[12] The AMMA program aims at improving the comprehension of the African monsoon dynamics at seasonal to inter-annual temporal scales [Redelsperger et al., 2006]. The Mali site is focused on surface processes, remote sensing of vegetation and SM. Four calibrated and checked SM stations (Table 1) from the super-site are used. They monitored SM at a 15 -minute time step. $65 \%$ of the studied region is characterized by undulating dune systems with moderate slopes represented by three stations: AGT at the top of a hillslope, BAG at intermediate elevation and AGB in bottom. In contrast, the EGU station is implemented on a flat rocky-loam plain representing $30 \%$ of the region.

[13] The AMMA-Mali site is located in the semi-arid Sahelian area. Climatic conditions are governed by the West African Monsoon with a long dryseason and a shorter rainy season from July to September (Table 1). The AMMA-Mali site is characterized by a mean annual rainfall of $370 \mathrm{~mm}$ per year (over 1920-2005). In 2005, monsoon dynamics allowed to have substantial rainfall and the cumulated 124 rainfall reached $441 \mathrm{~mm}$, of which $390 \mathrm{~mm}$ occurred in 125 June-September.

\subsection{AMSR-E Spacebased Measurements}

[14] The AMSR $E$ is a multi-channel passive microwave 128 instrument, on the Aqua satellite launched in May 2002. It 129 operates in polar sun-synchronous orbit with equator 130 crossings at 1:30 pm/am local solar time for ascending/ 131 descending orbits. Global coverage is achieved every two 132 days or less depending on the latitude. AMSR-E operates at 133 an incidence angle of $55^{\circ}$ at frequencies of $6.9,10.7,18.7,134$ 23.8, 36.5 and $89 \mathrm{GHz}$, all with $\mathrm{H}$ and $\mathrm{V}$ polarizations. The 135 data used are NASA level 3 where daily average of TB and 136 SM products, re-sampled to a global cylindrical $25 \mathrm{~km} 137$ Equal-Area Scalable Earth Grid (EASE-Grid) cell spacing. 138 [15] AMSR-E Radio-Frequency Interference (RFI) are 139 shown to affect large areas in North America and Japan at 140 C-band, while X-band signal is contaminated in England, 141 Italy and Japan [Njoku et al., 2005]. As a consequence the 142 original C and X-band retrieval algorithm was revised to 143 operate using only X-band. This leads to decreased per- 144 formances in SM retrieval. In this study AMSR-E volu- 145 metric SM products are used, as well as TB at 6.9 and 146 $10.7 \mathrm{GHz}$ at horizontal and vertical polarizations.

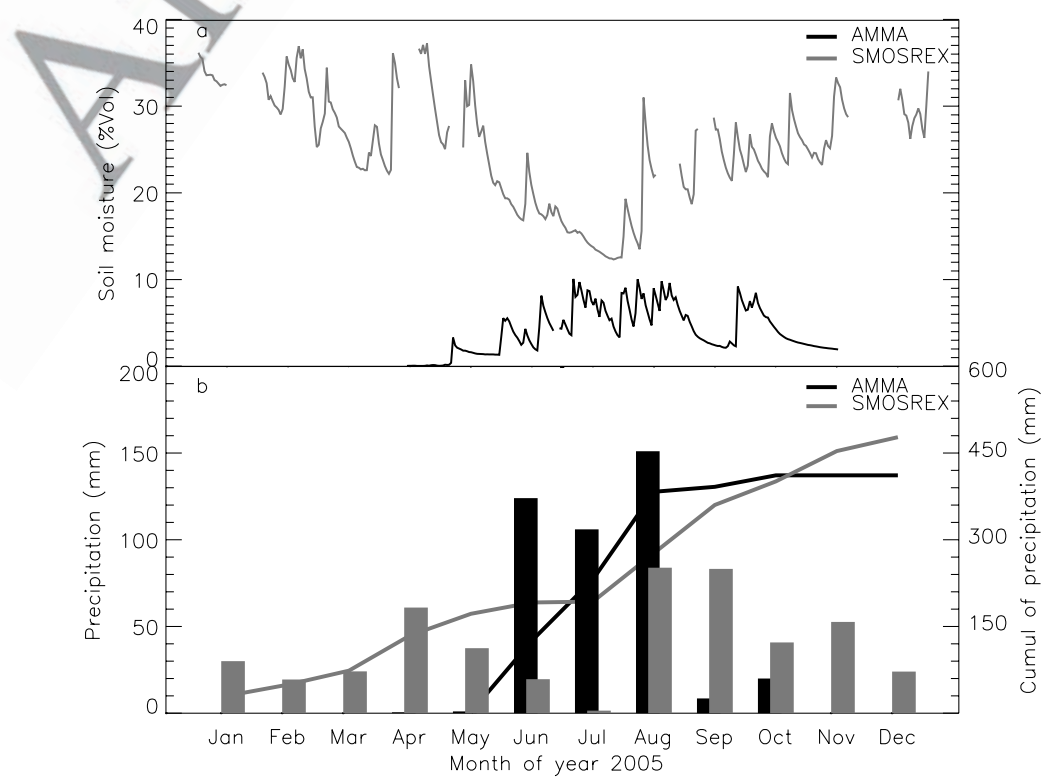

Figure 1. Annual cycle of (a) mean daily SM of all stations and (b) monthly mean and cumulated precipitation over SMOSREX (grey) and AMMA-Mali (black) sites. 
[16] According to [Njoku et al., 2003], the $\mathrm{H}$ and $\mathrm{V}$ polarizations enable calculation of the polarization ratio $(\mathrm{PR})$, which reduces the effects of soil temperature:

$$
P R=\frac{T B_{v}-T B_{h}}{T B_{v}+T B_{h}}
$$

The PR dynamics is mainly linked to SM and vegetation water content (VWC). But it must be interpreted with caution because SM and VWC have opposite effect on PR dynamics.

[17] In order to cover the ground measurement sites, the four-pixel average is used in the following analysis to evaluate AMSR-E products against ground measurements. Due to the AMSR-E products re-sampling, SM values of adjacent pixels are strongly correlated each other (94\% fir the two sites), with very low Root Mean Square Error (RMSE) of $0.38 \% \mathrm{~m}^{3} \cdot \mathrm{m}^{-3}$.

\section{Spatial Feature of Ground Soil Moisture}

[18] The most representative station can be identified with the methodology from Vachaud et al. [1985]. Based on statistical index of Mean Relative Difference (MRD). The use of the most representative station provides similar results to those obtained with the values of the four stations. But it allows to eliminate the accumulation of missing data. Best performance to represent the network average is obtained for a MRD value of zero. Stations with negative (positive) values of MRD underestimate (overestimate) surface SM. Standard deviation (STD) of MRD provides 174 information on the temporal stability of station. Lowest 175 STD and lowest absolute value of MRD indicate the most 176 representative station which is able to capture both temporal 177 variability and mean value of SM (Table 2). Thus, AUR 178 station as the most representative station. Surface SM 179 temporal dynamics, is a crucial component of the land 180 surface processes that controls the surface-atmosphere inter- 181 actions on different temporal scales ranging from diurnal 182 scale to seasonal and annual scales. Here the representativity 183 of a station is evaluated by considering its ability to capture 184 the surface SM dynamics. Accordingly, the AGT station, 185 with smallest STD, is the best representative station of 186 temporal dynamics of SM of the studied region.

\section{AMSR-E Soil Moisture Product Evaluation}

189

[19] AMSR-E data and ground data from the best 190 representative SM station are temporally co-located with 191 a 15-minute time step. Quantitative results of their com- 192 parison are provided in Table 3.

[20] For seasonal analysis, the year is split in four 194 periods. According to the monsoon timing they are chosen 195 as January-February-March (JFM), April-May-June 196 (AMJ), July-August-September (JAS) and October- 197 November-December (OND).

\subsection{SMOSREX}

[21] Figure 2a shows the temporal evolution of ground 200 based and AMSR-E SM products. AMSR-E SM values are 201 largely underestimated compared to those from ground 202 measurements. The annual mean value of AMSR-E SM 203 bias is $-9.63 \%$ in volumetric SM. The largest bias is 204 reached in fall and winter with $-12.0 \%$ and $-12.3 \%$ for 205 OND and JFM, respectively. Temporal variability of 206 AMSR-E SM products is also underestimated at the various 207 temporal scales. The amplitude of the SM annual cycle is 208 $11.35 \%$ for AMSR-E SM against $21.48 \%$ for the ground 209 measurements. In addition, the AMSR-E SM products 210 appear to be relatively noisy making the separation of 211 moderate SM increases from noise difficult.

[22] Normalized anomaly of surface SM is shown in 213 Figure $2 \mathrm{~b}$ for both AMSR-E products and ground measure- 214 ments. It is defined as the difference to the annual mean 215

Table 3. Comparison Between the Best Representative Ground Station and Different AMSR-E Products: SM and PR at 6.9 GHz and $10.7 \mathrm{GHz}$, at Annual and Seasonal Scales

\begin{tabular}{|c|c|c|c|c|c|c|c|}
\hline \multirow[b]{2}{*}{$\underline{\text { Period }}$} & \multirow[b]{2}{*}{ Site } & \multicolumn{2}{|c|}{ SM } & \multirow[b]{2}{*}{$R, \%$} & \multirow[b]{2}{*}{ PR6.9 R, \% } & \multirow[b]{2}{*}{ PR10.7 R, \% } & \multirow[b]{2}{*}{ Number of Data } \\
\hline & & RMSE, $\% \mathrm{~m}^{3} \mathrm{~m}^{-3}$ & Bias, $\% \mathrm{~m}^{3} \mathrm{~m}^{-3}$ & & & & \\
\hline YEAR & SMOSREX & 10.8 & -9.6 & $17.3^{\mathrm{a}}$ & $60.4^{\mathrm{a}}$ & $61.4^{\mathrm{a}}$ & 491 \\
\hline $\mathrm{t} 3.5$ & AMMA & 6.1 & 5.9 & $54.3^{\mathrm{a}}$ & $59.3^{\mathrm{a}}$ & $44.6^{\mathrm{a}}$ & 387 \\
\hline $\mathrm{t} 3.7$ & AMMA & 7.7 & 7.7 & 24.6 & 20.9 & -1.1 & 58 \\
\hline AMJ & SMOSREX & 8.7 & -7.9 & $81.1^{\mathrm{a}}$ & $74.8^{\mathrm{a}}$ & $78.9^{\mathrm{a}}$ & 132 \\
\hline t3.9 & AMMA & 6.5 & 6.3 & $62.9^{\mathrm{a}}$ & $72.7^{\mathrm{a}}$ & $73.4^{\mathrm{a}}$ & 103 \\
\hline $\mathrm{t} 3.10$ JAS & SMOSREX & 8.8 & -6.8 & 21.5 & $51.0^{\mathrm{a}}$ & $42.4^{\mathrm{a}}$ & 122 \\
\hline $\mathrm{t} 3.13$ & AMMA & 5.9 & 5.9 & $73.5^{\mathrm{a}}$ & $63.7^{\mathrm{a}}$ & 32.4 & 112 \\
\hline
\end{tabular}

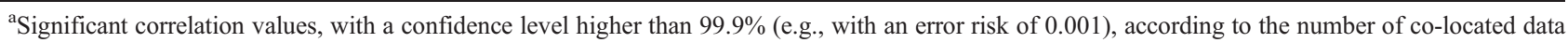
t3.14 used for each. 

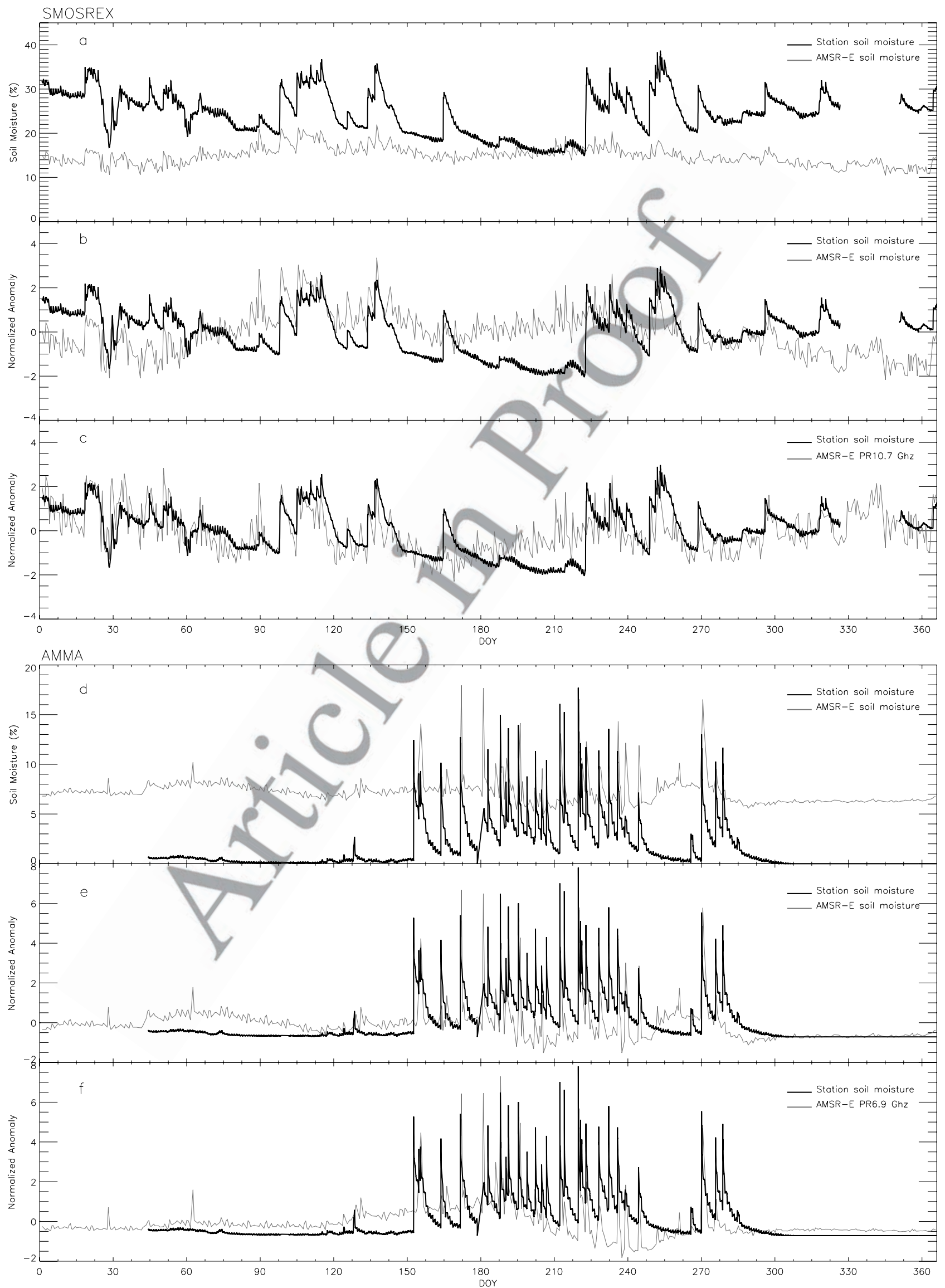

Figure 2 

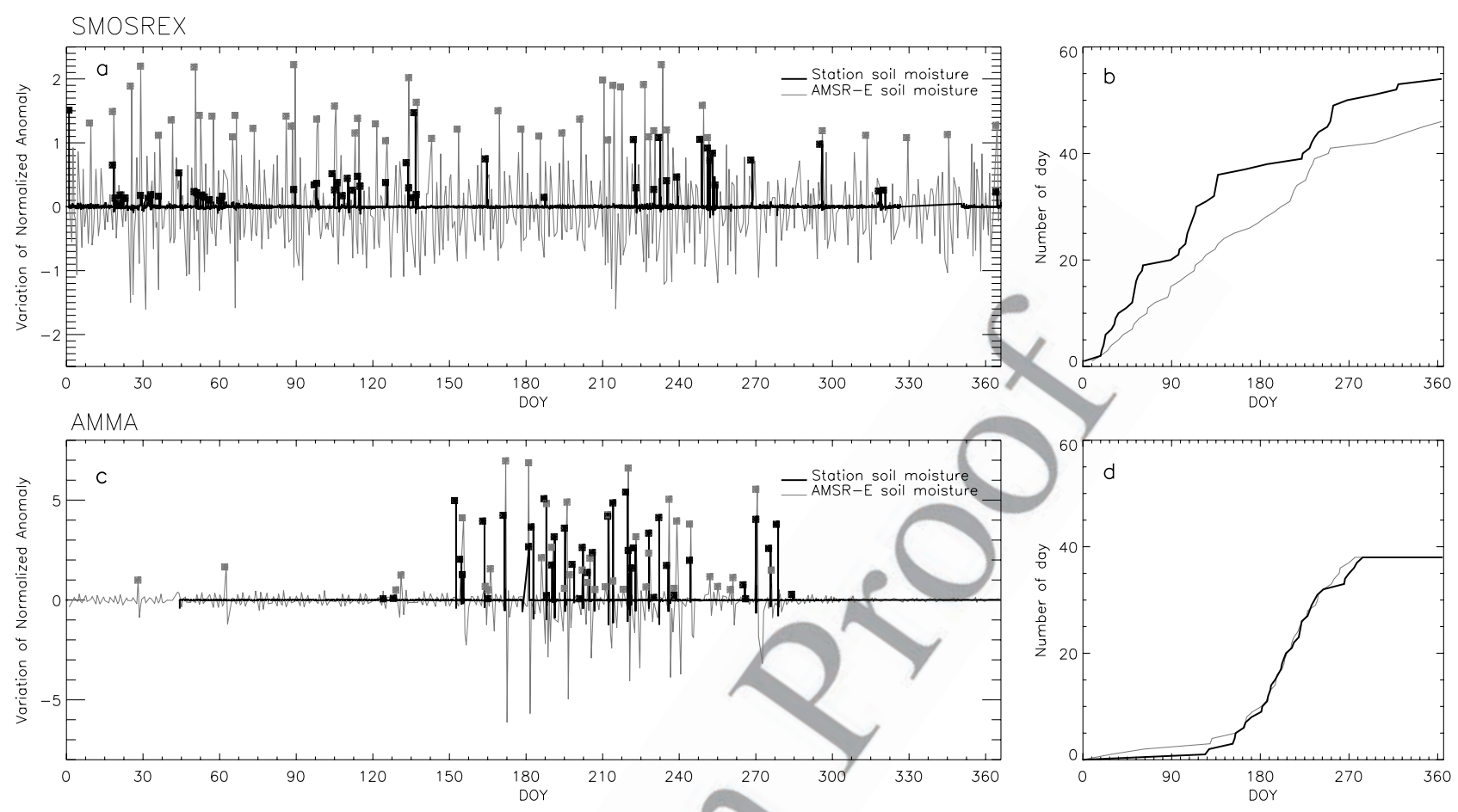

Figure 3. (left) Increments of standardized anomaly of SM from ground station (black) and AMSR-E product (grey), over (a) and (b) SMOSREX and (c) and (d) AMMA-Mali. Significant increments are indicated by a square. (right) Cumulated number days with significant positive increments.

divided by the standard deviation of the time series. Despite quite large noise, AMSR-E SM product provides good agreement with ground data in term of temporal variability. Table 3 indicates a significant correlation of $17.3 \%$ with an error risk at 0.001 , which is a good result according to diversity of climate conditions. The AMSR-E performances vary with the seasons ranging from $2.1 \%$ in JFM, to $81.1 \%$ in AMJ. In JAS, SM and VWC decrease. Accordingly, their contribution to the microwaves signal are opposite. SM dynamics contributes to increase TB while vegetation dynamics leads to decrease TB. In OND, poor correlation are not due to frozen event occurrence. During this season, SM and VWC increase, leading again to opposite effect on TB dynamics. In this conditions, where seasonal trend of SM and VWC are correlated, SM retrieval is made very challenging and requires to account with accuracy for the vegetation effect on the signal [de Rosnay et al., 2006]. These results show that the suitability of AMSR-E SM products to depict SM dynamics is depending on the season.

[23] In contrast to SM products, PR at both $6.9 \mathrm{GHz}$ and $10.7 \mathrm{GHz}$ are well correlated with the in-situ observations. At the annual scale correlation values are $60.4 \%$ and $61.4 \%$ at $\mathrm{C}$ and $\mathrm{X}$-band, respectively. Results at the seasonal scale also indicate significant correlation values for any term of the year for both frequencies. The best agreement is provided by X-band measurements in spring time (AMJ), with a $78.9 \%$ correlation, as clearly shown in Figure 2c. This indicates the suitability of AMSR-E PR products to capture normalized SM dynamics over this site at seasonal 244 and annual scales.

[24] Figure 3a shows the ability of AMSR-E products to 246 capture SM variations at the precipitation event scale. Based 247 on normalized SM anomalies, a threshold is used to filter 248 out signal noise and low SM increases from significant SM 249 variations. Based on data monitored during dry period it is 250 fixed to be 0.1 for ground measurements and 1.0 for 251 AMSR-E SM products. Positive increments larger than 252 the threshold, represented by squares on the figure, are 253 related to relatively important precipitation occurrence. 254 Figure $3 \mathrm{~b}$ shows the cumulated number of days where 255 positive SM increments is obtained, for both AMSR-E 256 and ground measurements of SM. Ground measurements 257 indicate 54 days with significant positive increments. 258 According to field observation of precipitation, they corre- 259 spond to precipitation events larger than $2 \mathrm{~mm}$, which 260 represent $90 \%$ of the annual rainfall.

\subsection{AMMA-Mali}

[25] Similar analysis is conducted for the AMMA-Mali 263 site. AMSR-E product, which is overestimated, does not 264 capture the correct range of SM (Figure 2 (bottom)). Bias on 265 volumetric SM is $5.9 \%$ at the annual scale (Table 3). The 266 lower bias is obtained during rainy season and the higher 267 bias is obtained during dry season $(4.7 \%$ in JAS and $7.7 \% 268$ in JFM). AMSR-E SM product presents a minimum SM 269 threshold, which is inconsistently higher during the dry 270

Figure 2. Comparison for (top) SMOSREX and (bottom) AMMA-Mali between the best representative station (black) and AMSR-E product (grey): (a) and (d) SM absolute values, (b) and (e) SM normalized values, and (c) and (f) PR normalized values. 
season (about 7\%) than during then rainy season (about $5 \%$ ). Despite of this, the annual cycle of AMSR-E volumetric SM product is shown to capture large SM increases related to strong precipitation events occurring in the monsoon season.

[26] Normalized values of SM are shown in Figure 2e. Corresponding significant correlation is indicated in Table 3 to be $54.3 \%$. Lower values of correlation are obtained in dry season $(24.6 \%$ in JFM) due to signal noise which is larger than SM variations in this season. But significant correlation values obtained in AMJ (62.9\%), JAS (53.5\%) and OND $(73.5 \%)$ are particularly noteworthy when SM dynamics is more important. All of the correlation values are significant, indicating that AMSR-E SM products is able to capture efficiently the SM dynamics over this Sahelian site, at both annual and seasonal scales.

[27] PR products are significantly correlated to ground SM at the annual scale, with values of $59.3 \%$ and $44.6 \%$ for C-band and X-band respectively. As for SM products, best agreement between PR and ground SM are obtained during the monsoon season, with correlation values of $66.7 \%$ at C-band and $60.6 \%$ at X-band. Figure $2 \mathrm{f}$ confirms this good agreement, showing normalized $\mathrm{C}$-band $\mathrm{PR}$ and ground SM.

[28] Figure 3c shows the evaluation of AMSR-E SM products at the rainfall event scale. For this site, the minimum threshold to consider increments of normalized $\mathrm{SM}$ is determined based on dry season data to be 0.05 and 0.5 for ground station and AMSR-E SM product, respectively. AMSR-E SM product indicate that 38 days of the year present a positive increment, also detected by ground measurements, which is consistent with precipitation data. Moreover, a very good agreement concerning their temporal distribution is shown by Figure 3d. Accordingly AMSR-E SM product is shown to capture with a high degree of accuracy the occurrence of SM increases at the precipitation event scale over AMMA-Mali.

\section{Conclusion}

[29] This paper investigates the ability of AMSR-E products provided by the NASA, to capture the ground SM over two sites.

[30] For both sites AMSR-E SM products and polarization ratio are shown to be noisy, particularly at the daily scale, and the absolutes values of SM are not captured (Figures $2 \mathrm{a}$ and $2 \mathrm{~d}$ ). Ground measurements are underestimated by AMSR-E SM product over the SMOSREX site and overestimated over the AMMA-Mali site (Table 3). The amplitude of volumetric SM provided AMSR-E products, is shown to be underestimated over both sites. Nevertheless, AMSR-E SM product captures the SM temporal variability (Figures 2b and 2e).

[31] However, this paper shows that polarization ratios at $\mathrm{C}$ and $\mathrm{X}$-band are more suitable than SM product to capture the SM dynamics over the two sites. Indeed, due to serious contamination by RFI, multi-source information provided by the different operating frequencies of AMSR-E is not fully used in the NASA AMSR-E processing chain. In particular, C-band data, which are highly relevant for SM retrieval, are not used, limiting thereby the performances of the algorithm.
[32] At the precipitation event scale, it is shown that 332 AMSR-E performs very well to detect occurrence of SM 333 variation over AMMA-Mali site, with a perfect agreement 334 of the timing as shown by the Figures $3 \mathrm{c}$ and $3 \mathrm{~d}$. This good 335 performance is particularly noteworthy and very promising 336 for the use of AMSR-E product in Sahelian area. 337

[33] The results presented in this paper clearly show that, 338 (1) the polarization ratio product is in better agreement with 339 ground measurements than SM products (2) ability of 340 AMSR-E to retrieve SM in the studied temperate areas 341 must be taken with care but temporal variability of surface 342 SM is captured by the PR, (3) AMSR-E is highly suitable 343 for SM remote sensing over semi-arid areas. It is shown to 344 capture the SM variability in term of normalized SM values, 345 at any temporal scale.

[34] The future SMOS sensor, with higher sensitivity to 347 SM due to L-band measurements, is expected to provide 348 improved accuracy in SM variability retrieval, as well as in 349 term of volumetric SM.

[35] Acknowledgments. The authors thank the SMOSREX and 351 CarboEurope-IP field experiments. Based on a French initiative, AMMA 352 was built by an international scientific group and is currently funded by a 353 large number of agencies, especially from France, the UK, the US, and 354 Africa. It has been the beneficiary of a major financial contribution from 355 the European Community's Sixth Framework Research Programme 356 $\begin{array}{ll}\text { (http://www.amma-international.org). } & 357\end{array}$

\section{References}

de Rosnay, P., et al. (2006), SMOSREX: A long term field campaign 359 experiment for soil moisture and land surface processes remote sensing, 360 Remote Sens. Environ., 102, 377-389. 361

Dolman, A. J., et al. (2006), CERES, the CarboEurope Regional Experi- 362 ment Strategy in les Landes, south west France, Bull. Am. Meteorol. Soc., 363 $87,1367-1379$.

Engman, E. T. (1990), Progress in microwave remote sensing of soil moist- 365 ure, Can. J. Remote Sens., 16, 6-14. 366

Entekhabi, D., et al. (2004), The Hydrosphere State (Hydros) satellite mis- 367 sion: An Earth system pathfinder for global mapping of soil moisture and 368 land freeze/thaw, IEEE Trans. Geosci. Remote Sens., 42, 2184-2195. 369 Kerr, Y. H. (2007), Soil moisture from space: Where are we?, Hydrogeol. J., 370 $15,117-120$.

Kerr, Y. H., P. Waldteufel, J.-P. Wigneron, J.-M. Martinuzzi, J. Font, and M. 372 Berger (2001), Soil moisture retrieval from space: The Soil Moisture and 373 Ocean Salinity (SMOS) mission, IEEE Trans. Geosci. Remote Sens., 39, 374 1729-1735. 375

Koster, R. D., et al. (2004), Regions of strong coupling between soil 376 moisture and precipitation, Science, 305, 1138-1140. 377

Njoku, E. G., and D. Entekhabi (1996), Passive microwave remote sensing 378 of soil moisture, J. Hydrol., 184, 101-129.

Njoku, E. G., T. Jackson, V. Lakshmi, T. Chan, and S. Nghiem (2003), Soil 380 moisture retrieval from AMSR-E, IEEE Trans. Geosci. Remote Sens., 41, 381 215-229. 382

Njoku, E. G., P. Ashcroft, T. K. Chan, and L. Li (2005), Global survey and 383 statistics of radio-frequency interference in AMSR-E land observations, 384 IEEE Trans. Geosci. Remote Sens., 43, 938-947. 385

Redelsperger, J.-L., C. Thorncroft, A. Diedhiou, T. Lebel, D. Parker, and J. 386 Polcher (2006), African Monsoon Multidisciplinary Analysis (AMMA): 387 An international research project and field campaign, Bull. Am. Meteorol. 388 Soc., 87, 1739-1746. 389

Vachaud, G., A. Passerat De Silans, P. Balabanis, and M. Vauclin (1985), 390 Temporal stability of spatially measured soil water probability density 391 function, Soil Sci. Soc. Am. J., 49, 822-828.

J.-C. Calvet, Météo-France, 42 avenue G, F-31057 Toulouse, France. 394 E. Ceschia, C. Gruhier, Y. Kerr, E. Mougin, and P. Richaume, Centre 395 d'Etudes Spatiales de la Biosphère, 18 Av. E. Belin, F-31401 Toulouse, 396 France. (claire.gruhier@cesbio.cnes.fr)

P. de Rosnay, ECMWF, Reading RG2 9AX, UK. 398 